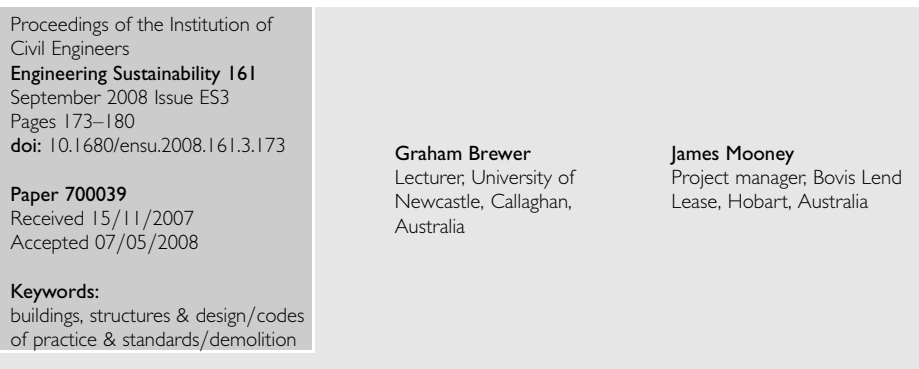

\title{
A best practice policy for recycling and reuse in building
}

\section{G. Brewer MSc, MCIOB and J. Mooney BConst. Mgnt}

Industrial ecologists, recognising the impact of industry on the environment, have developed reduction strategies including the reuse and recycling of materials. World wide, the reduction of natural resource consumption has been investigated and applied to various industries with varying degrees of success. This paper focuses on the construction industry, using thematic analysis to locate the world's best practice with respect to construction and demolition (C\&D) waste legislation. It identifies the Netherlands and Denmark as current leaders in C\&D waste management and reports on the results of a policy analysis, which concluded that landfill levies, landfill material bans, material segregation and certification are the main contributors to waste reduction. A meta-analysis of Australian state legislation reveals that these policies are largely absent, rendering current legislation ineffective. A model of legislative best practice is presented that is applicable to the Australian context and which incorporates the concept of designing for disassembly-a technique that already exists in other manufacturing industries. By implementing these policies, there is potential to decrease waste through reuse and recycling within the building industry.

\section{INTRODUCTION}

The quantity of waste produced by the demolition of residential and industrial buildings presents a profound challenge for governments around the world. It has been estimated that the USA and Western Europe alone produce 'half a tonne of construction waste and demolition debris per capita annually'. ${ }^{1}$ Australia is one of the worst landfill offenders, generating almost $1 \mathrm{t}$ per person per year or approximately $14 \mathrm{Mt}$ of waste every year. An average of $28 \%$ of this is associated with construction and demolition (CED) activities. ${ }^{2}$ At best, $10 \%$ of this waste material is reused, a further $60 \%$ is recycled and the remaining $30 \%$ is deposited in landfill. ${ }^{3}$

As understanding of environmental issues increases, more emphasis is being placed on the recycling or reuse of CED waste. ${ }^{4}$ The main drivers for this include limited land availability for landfill and harmful leachate and contaminants leading to groundwater contamination. However, it is the continuous drain on the environment and its ability to sustain our requirements that drives a continual reassessment and reform of waste disposal and policies relating to it.
The roots of Australia's apparent reticence to engage enthusiastically with a reduction in rates of landfill are complex and controversial. Certainly, the blurring of federal/state boundaries of responsibility is a consideration, as is the tension between developers and environmentalists. Moreover, there is a wide disparity between estimates of the cost of carbon use by, for example, the Australian Productivity Commission (A \$12-15/t $(£ 5 \cdot 50-7))^{5}$ and others such as Sir Nicholas Stern (A \$110/t (£51)). ${ }^{6}$ This reflects the different extent to which policy decisions take into account the impact of climate change on environmental, health, industrial, agricultural and infrastructure costs.

The challenge facing the Australian government is how to reduce the amount of CED waste and what to do with waste that is considered unavoidable. ${ }^{7}$ Kibert and $\mathrm{Chini}^{8}$ found that waste reduction can be achieved through changes in building design and government policy, addressing issues such as design for disassembly and building codes that require such consideration. Teo and Loosemore ${ }^{7}$ believe there are three options for managing unavoidable waste-reuse, recycling and disposal-and contend that the balance between them must be driven by legislative requirements on particular materials, the types of materials being wasted and the economic viability of recovery/ disposal processes.

It is common for developed countries to have legislation regarding waste management. Some are stand-alone policies relating to a single country, such as those found in Canada and the USA, while others are developed under the umbrella of a unified agreement, such as those in force across the European Union (EU) member states. ${ }^{9}$ There is no international agreement on best practice for C\&D waste disposal. In the USA, 92\% of the $136 \mathrm{Mt}$ of CetD waste produced annually is usually placed in landfill. $^{8}$ By contrast, the Netherlands produces $18 \mathrm{Mt}$, of which $90 \%$ is recycled, reused or incinerated. ${ }^{10}$ In Denmark and Belgium, 90\% of building waste is recycled or reused. ${ }^{11}$ With a recycling or reuse rate of below 70\%, it is apparent that Australia can learn from other countries.

\section{BACKGROUND}

Industrial ecologists recognise the impacts of industry on the environment and have developed methods to reduce them by, for example, material substitution, recycling and waste mining. However, the construction industry has not explored these ideas fully. As put by Crowther, ${ }^{12}$ 
If the once-through life-cycle [Fig. 1] of resource use that dominates the construction industry is replaced with a true cycle in which materials and components are reused, the environmental impact of the industry could be drastically reduced.

The disposal alternatives for C\&D waste range from recycling to landfilling. Fig. 2 illustrates the 'least-worst' philosophy common throughout Europe, America and Australia, which highlights the minimisation of environmental damage and resource consumption. ${ }^{13}$ The optimal outcome, aside from non-consumption, is 'cradle to cradle' material and component reuse as expressed philosophically by McDonough and Braungart. $^{14}$

Within the EU, CED waste accounts for approximately 34\% or $180 \mathrm{Mt}$ of all waste produced annually. ${ }^{7}$ Of this, $130 \mathrm{Mt}$ is sent to landfill or incinerated. However, recycling rates vary between member states ${ }^{11}$ and this can largely be attributed to legislative variations. The most stringent legislation imposes reusing/ recycling $90 \%$ of CED waste and makes illegal the landfilling of materials that can be recycled or reused. ${ }^{10,11}$

Waste generated from CED activities has been recognised as a major concern in Australia. ${ }^{5,15-17}$ As a member of the Australian and New Zealand Environment Conservation Council (Anzacc) formed in 1992, Australia committed itself to 50\% reduction in solid landfill waste by the year 2000 , with $40 \%$ consisting of CAD waste. ${ }^{15,18}$ Different states and territories then proceeded to set their individual targets. ${ }^{19}$

Australian governments' initiatives include the WasteWise construction programme, an agreement with five major building companies intended to identify best practice in waste prevention or reuse. ${ }^{20}$ The government is also responsible for producing the Building Code of Australia, the primary regulatory instrument

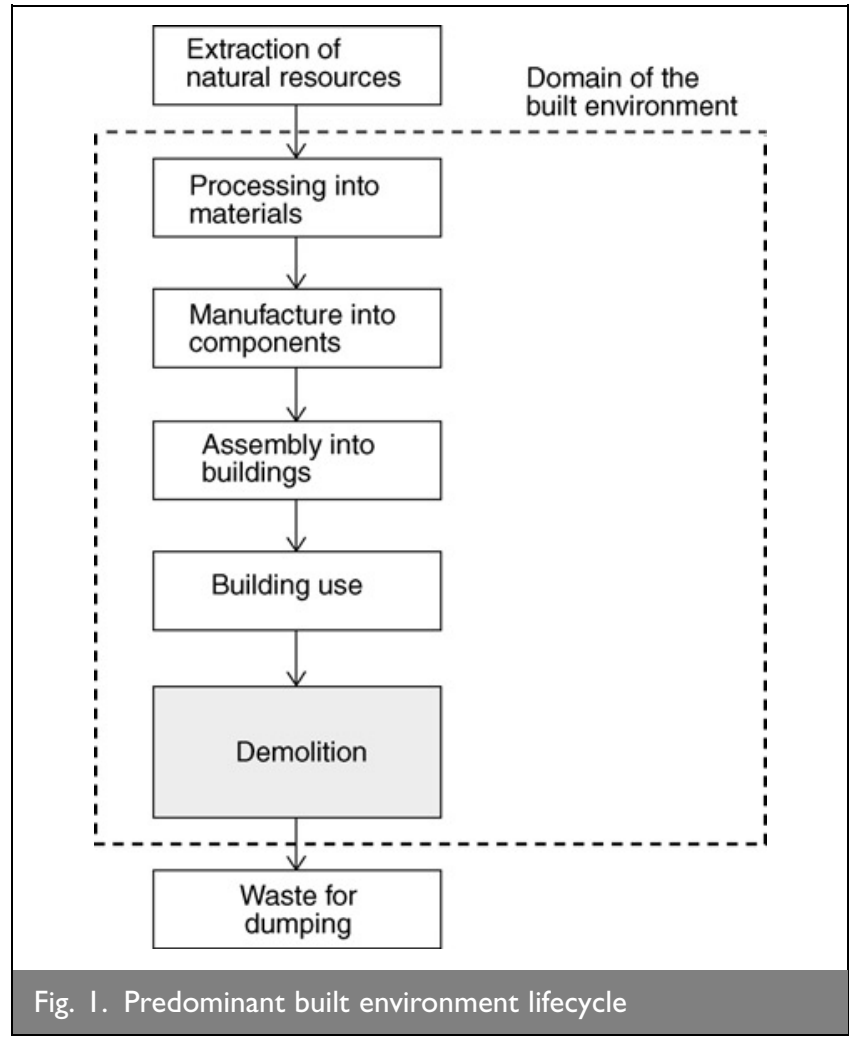

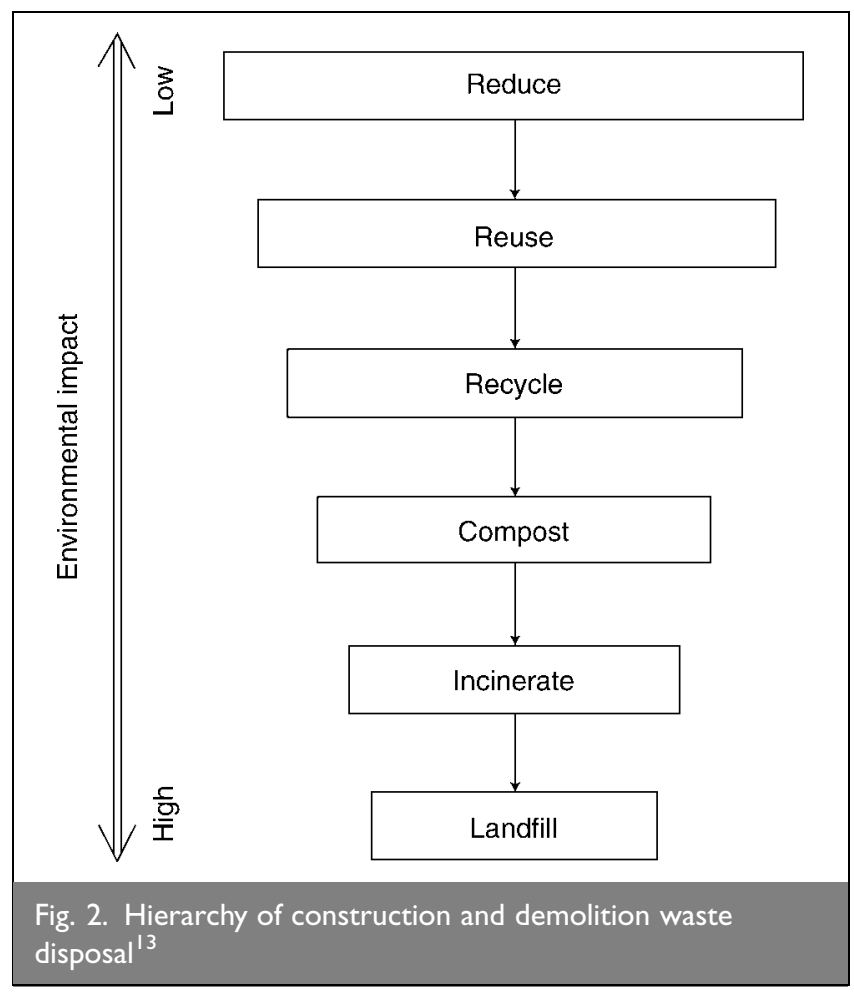

governing the construction of new and refurbished buildings; this code does not cover recycling, reuse of materials or the concept of deconstruction. ${ }^{18}$ The New South Wales (NSW) Department of Environment and Conservation has begun to target CAD waste, but confines its attention to governmentfunded projects. ${ }^{21}$ The government has stated a wish to improve Australia's reuse and recycling in construction. Its initiatives have, however, been ambiguous and broad in application, pushing responsibility to the states, territories and local government. ${ }^{18}$

A popular theory for the avoidance or reduction of CAD waste is the design for disassembly or deconstruction of buildings. Disassembly is, as it sounds, the reverse of assembly and would require a similar amount of time and effort and (reverse) construction sequence, but would lead to the ability to recycle or reuse construction components. ${ }^{18}$ Disassembly offers advantages over traditional demolition, including the 'diversion of waste from landfill areas, increased ease of material recycling and enhanced environmental protection'. ${ }^{8}$ The theory has been successfully put into practice in areas of manufacturing. ${ }^{22}$ 'Zero landfill' is based on the idea of a closed-loop system where products are regarded as valuable resources and an all-out effort is made to reuse them.

Research in the USA has indicated that design for disassembly in the construction industry is best driven by government policy. ${ }^{8}$ Other research suggests that the Netherlands and Denmark have set a benchmark in terms of CED waste management with reuse/ recycling rates of around 90\%. ${ }^{23-26}$ In comparison, Australia lags behind with a best state rate of $70 \% .^{27}$

This raises a number of important questions.

(a) Do these European nations represent the model of world's best practice? 
(b) If they do, to what extent is this driven by statutory regulation that encourages design for disassembly strategies?

(c) In terms of policy, how does Australia compare to the rest of the world?

(d) Can lessons be learnt from other nations and successfully applied in an Australian context?

\section{RESEARCH PROCESS}

This research set out to model world's best practice in C\&D waste legislation for application in Australia. The objectives were therefore

(a) to develop an appropriate methodology for identifying and analysing suitable policy documents

(b) to identify leading waste reduction and disposal techniques from construction and other industries

(c) to examine current Australian policies on C\&D waste in order to conduct a legislative gap analysis relative to world's best practice, thereafter proposing a model for Australian best practice.

Consideration was give to legislative 'portability' and applicability in an Australian context. The processes and their interrelationships are illustrated in Fig. 3. Given the text-based nature of the data used in this study, thematic analysis techniques utilising open and axial coding were used throughout. ${ }^{28}$

\section{WASTE DISPOSAL AND REDUCTION ANALYSIS}

Initial research using only journals focusing on construction highlighted the negative impact of CAD waste on the environment. A thematic analysis was then conducted to further investigate this topic. Open coding was used to identify salient issues to guide subsequent information gathering and development of theory. ${ }^{29,30}$
The analysis included the current waste output performance of Australia and other countries. The choice of countries was based on ability to obtain accurate and credible information from statistical bureaus, peer-reviewed journals, conference proceedings and commonly referenced works from within these sources. This analysis was used to ascertain the countries demonstrating best waste management practice.

The thematic analysis was extended to look at the current literature on recent developments of waste management practices in industries outside of construction. The theory of design for disassembly emerged as an important feature from this analysis.

Seven companies from the automotive, electronic, packaging and food distribution sectors were analysed using data collected from their own websites, supported by journal articles. The usefulness of this information was not based solely on the companies' claimed successes but in the fact that their experiences were achievable, verifiable and potentially transferable to the construction industry. Using axial coding to develop thematic detail, a theoretical framework was developed for designing for disassembly. This framework was then added to the current methods of waste management, thus echoing Manuel $^{31}$ who successfully used a similar method when investigating environmental concerns of waste disposal and management. Thereafter, the policy analysis used this framework to identify the extent to which various pieces of policy and legislation embodied the principles contained within it.

\section{POLICY ANALYSIS}

Policy information for countries representative of best practice was collected during the first half of 2006 using government policy websites on waste management. The data collected were then organised using the levels of importance imposed on them by the respective governments and subsequently compared and categorised. In order to temper any bias in these sources, secondary documentation (including journal articles and conference proceedings) was used to corroborate the validity of the information. The results of this policy analysis were used as the framework for a comparison with Australian policy.

A similar process was undertaken to investigate the topic of Australian waste management using policy websites, journals, conference proceedings and government reports. However, this analysis focused directly on criteria determined by the analysis of waste management best practice. The results documented the similarities and differences between the 
countries and were used to provide an indication of those areas of policy requiring improvement.

\section{RESULTS}

\section{I. The Netherlands}

Political and social resistance in the late 1980s forced the Dutch government to shelve the planning and construction of more landfill and incineration sites and, as a result, inland barges were used to store waste for a period of time. These factors were the main issues driving the development and implementation of a national waste management plan. ${ }^{26}$

The plan drives the prevention and recovery of all waste, including CED waste, leading to a national recycling rate of $90 \% .{ }^{26}$ Material recovery is preferable as it requires reuse and recycling; where this is not feasible, waste can be used for fuel. This order of preference is based on Lansink's ladder. ${ }^{13,26}$ There are three main policies within the national waste management plan to encourage the prevention and recovery of CED waste.

(a) Building Materials Decree (BMD). A crucial element in the reduction of CED waste in the Netherlands was ensuring that there was a market for the secondary materials produced from waste through the BMD, which was developed to provide customer confidence in the products. The BMD prevents soil and surface water pollution and came into full operation on 1 July 1999. This response to waste management legislation, which enforces the maximal reuse and recycling of materials, applies quality standards to reused materials. ${ }^{23}$ It makes no differentiation between primary materials, newly extracted or produced products and secondary materials that come from demolished structures. All materials must conform to the required standards and be properly certified. ${ }^{32}$ The implementation of the BMD has greatly improved levels of recycling of secondary materials in the Netherlands and has helped in raising the level of reused materials. ${ }^{23}$

(b) The Environmental Taxes Act gradually increased the level of taxation of waste sent to landfill until 2002. At this point, landfill tax per tonne was more expensive than the government's desired alternatives of recovery or incineration-'a significant financial incentive had thus been created to use building and demolition waste beneficially'. ${ }^{26}$

(c) The Waste Substances (Prohibition of Landfill) Decree 32 bans all landfill of recyclable waste products produced by CED. The only CED waste sent to landfill will be noncombustible and non-recyclable waste on which a high tax is paid. ${ }^{26}$

\subsection{Denmark}

In 1993, 50\% of CED waste was recycled, 23\% was disposed of via incineration and energy recovery and 27\% was landfilled. Realising this was a misuse of valuable resources and that landfilling was having a polluting effect on the country's groundwater system (which provided 98\% of Denmark's water supply), high priority was given to waste management. ${ }^{25}$ Current figures indicate that Denmark has achieved a recycling level of $90 \%$, incineration levels of $2 \%$ and landfill levels of $8 \% .^{24}$
The Danish policy model, called the Environmental Protection Act (EPA), is formed around the Danish hierarchy of waste management priority of options: 'recycling ranks higher than incineration with energy recovery, and landfilling ranks lowest'. ${ }^{24}$ Related legislation reduces pollution, promotes recycling and limits waste disposal and restricts the use and waste of raw materials. ${ }^{25}$ The tools to enforce the act's policies include the following.

(a) The Landfill Prohibition Order prevents the landfilling of any substance or waste product suitable for incineration, thus ensuring the recovery of energy contained in waste and preventing groundwater pollution. The future plan for this policy is to shift the focus from incineration to recycling. ${ }^{24}$

(b) The Waste Tax is an economic instrument designed to reduce all waste, including C\&D waste. It is a hierarchical system that differentiates between wastes for recycling (taxexempt), wastes for incineration and wastes that go directly to landfill (the most expensive). ${ }^{24}$

(c) The Waste Separation Circular ${ }^{25}$ is an agreement between the Ministry for Environment and Energy, the EPA, local authorities, the Danish Construction Association and the Danish Demolition Association. It states 'in demolition works involving more than $1 \mathrm{t}$ of construction and demolition waste, waste shall be separated at source in clean fractions' ${ }^{24}$

\section{AUSTRALIAN POLICY ANALYSIS AND IDENTIFICATION OF THEMES}

Analysis of CED waste legislation and policies of the Netherlands and Denmark indicated two areas of commonality and two areas of difference. The following criteria were included to measure Australian CED waste practice against world's best practice:

(a) landfill levy-landfill is the most expensive option; recycled materials are exempt

(b) landfill material ban-ban on dumping all recyclable waste

(c) material certification-developing material standards or certification to allow for reuse

(d) material segregation-segregation of materials allows for more extensive recycling.

The responsibility for waste management in Australia straddles three different levels of government: local, state and commonwealth. The federal government has provided the framework for policy direction by setting targets for waste reduction through Anzacc agreements, overseen in Australia by the Environment Protection and Heritage Council (EPHC). Local governments are responsible for waste collection and the provision of waste and recycling facilities. In general, however, it is state governments that regulate waste management, including C\&D waste. With so many parties involved in the process, 'the waste management policy for Australia is for the most part, poorly coordinated. ${ }^{33}$ Table 1 outlines the state waste management and recycling legislation and policies for CED waste in selected states (statistical information was not available for Tasmania, the Northern Territory and Australian Capital Territory).

\section{I. New South Wales (NSW)}

The primary pieces of waste management legislation used in NSW are the Waste Minimisation and Management Act 1995, 


\begin{tabular}{|c|c|c|}
\hline & Legislation & Policy \\
\hline New South Wales & $\begin{array}{l}\text { - Waste Minimisation and Management Act } \\
\text { 1995 } \\
\text { - Protection of the Environment Operations } \\
\text { Act } 1997 \\
\text { - Protection of the Environment Operations } \\
\text { Act (Waste Regulations 2005) }\end{array}$ & $\begin{array}{l}\text { - Construction and demolition waste action } \\
\text { plan } 1998 \\
\text { - Waste reduction and purchasing policy } \\
\text { (Wrapp) } 1997 \\
\text { - NSW waste avoidance and resource } \\
\text { recovery strategy } 2003\end{array}$ \\
\hline Victoria & - Environment Protection Act 1970 & $\begin{array}{l}\text { - EcoRecycle Victoria } \\
\text { - Towards zero strategy }\end{array}$ \\
\hline South Australia & - Environment Protection Act 1993 & $\begin{array}{l}\text { - Environment protection (waste } \\
\text { management) policy I } 994 \\
\text { - Zero waste strategy }\end{array}$ \\
\hline Queensland & - Environment Protection Act 1994 & $\begin{array}{l}\text { - Waste management strategy for Queensland } \\
1996\end{array}$ \\
\hline Western Australia & $\begin{array}{l}\text { - Environmental Protection Amendment Act } \\
1998 \\
\text { - Environmental Protection (Landfill) Levy Act } \\
1998\end{array}$ & $\begin{array}{l}\text { - Waste reduction and recycling waste policy } \\
2020\end{array}$ \\
\hline
\end{tabular}

Protection of the Environment Operations Act (Waste

Regulations 2005) which is supported by waste reduction and purchasing policy (Wrapp) 1997, the construction and demolition waste action plan 1998 and the NSW waste avoidance and resource recovery strategy 2003 . The current recycling rate for CED waste is $65 \%$ and the aim of these policies is to increase this figure to $75 \%$ by $2014 .^{34}$

The NSW landfill levy on C\&D waste is currently $\$ 15 / \mathrm{t}(£ 7 / \mathrm{t})$ (rural) and $\$ 22.70 / \mathrm{t}(£ 10 \cdot 50 / \mathrm{t}$ ) (metro), although there are plans to increase the levy to $\$ 57 / \mathrm{t}(£ 26 \cdot 50 / \mathrm{t}$ ) by 2012 . It is believed this increase in revenue will provide a boost to technologies aimed at achieving the state's waste targets. Working alongside the levy system is the rebate from waste levy, which can be claimed if waste leaves the facility recycled or genuinely reused. ${ }^{33}$ There is no legislation or policies covering the rest of these measures with respect to CED. Wrapp, which is directed towards all state-owned agencies and corporations, requires these bodies to provide data on waste types generated and the amounts recycled. It also recommends waste separation and the use of recycled products. ${ }^{35}$

\subsection{Victoria}

Waste management legislation in Victoria centres on the Environment Protection Act 1970, reinforced by the policies of EcoRecycle Victoria and the towards zero strategy. ${ }^{27}$ In $2004-$ 2005 , Victoria produced approximately $3 \cdot 1 \mathrm{Mt}$ of CED waste, with $57 \%$ being recycled. The intent of current policies is to increase this rate to $80 \%$ by $2014 .^{27}$

There is no current legislation or policies regarding landfilling, waste separation or material certification of recyclable CAD waste in Victoria. The government's in-house purchasing procedure (towards zero strategy) recognises this and makes recommendations. ${ }^{27}$ Higher levies on waste are used to fund the waste management programme EcoCycle. ${ }^{33}$

\subsection{South Australia}

The Environment Protection Act 1993 is South Australia's primary waste management legislation and is supported by the zero waste strategy. With the current recycling rate of C\&D waste at approximately 55\%, the aim is to increase this figure to $100 \%$ with implementation of this strategy. ${ }^{36}$

No distinction is made between CED waste and municipal waste in landfill levies. The main purpose of the levy is to fund waste management programmes rather than reduce landfill. ${ }^{33}$ There is no current legislation or policy covering the rest of these measures with respect to CAD. The proposed zero waste strategy is intended to prevent the dumping of waste that includes recyclable products by providing appropriate infrastructure and a well-established market, thereby encouraging segregation and certification. $^{36}$

\subsection{Queensland}

Waste management for Queensland is controlled by the Environment Protection Act 1994 and supported by the waste management strategy for Queensland 1996. The current C\&D waste recycling figure is $42 \% .^{33}$

There are no current levies on C\&D waste disposal in Queensland, ${ }^{18}$ nor any methods to prohibit the landfilling of recyclable CAD waste. The closest comparison is the government's in-house waste management strategy objective, in which the demolition of a government building or any site redevelopment by a government agency will, where practicable, include a waste recovery programme for all reusable materials. ${ }^{18}$

\subsection{Western Australia}

The primary legislation for waste management in Western Australia is in the form of the Environmental Protection Amendment Act 1998 and the Environmental Protection (Landfill) Levy Act 1998. These are supported by the waste reduction and recycling waste policy 2020. In 2003-2004, the recycling rate for CED waste was $21 \%$; it is the intent of the government to increase this to $100 \%$ by the year $2020 . .^{33}$

The landfill levies in place in Western Australia are used to fund the waste management programme. ${ }^{33}$ No current legislation or policies covering the rest of these measures with respect to CAD wastes are in place. 


\begin{tabular}{|c|c|c|c|c|c|}
\hline & \multirow[b]{2}{*}{$\begin{array}{l}\text { Recycling rate of } \\
\text { C\&D waste: \% }\end{array}$} & \multicolumn{2}{|c|}{ Landfill levy } & \multirow[b]{2}{*}{$\begin{array}{l}\text { Material } \\
\text { certification }\end{array}$} & \multirow[b]{2}{*}{$\begin{array}{l}\text { Material } \\
\text { segregation }\end{array}$} \\
\hline & & Most expensive & $\begin{array}{l}\text { Landfill materials } \\
\text { ban (levy exempt) }\end{array}$ & & \\
\hline Netherlands & 90 & Yes & Yes & Yes & No \\
\hline Denmark & 90 & Yes & Yes & No & Yes \\
\hline New South Wales & 65 & No & No & No & No \\
\hline Victoria & 57 & No & No & No & No \\
\hline South Australia & 55 & No & No & No & No \\
\hline Queensland & 42 & No & No & No & No \\
\hline Western Australia & 21 & No & No & No & No \\
\hline
\end{tabular}

\section{DISCUSSION}

The policy analysis of the Netherlands and Denmark-considered to be exemplars in C\&D waste recycling-identified the employment of four major waste management strategies, that is landfill levies, landfill material bans, waste separation and material certification for reuse. Table 2 presents a summary of these findings, comparing world's best practice and five state governments within Australia. It should be noted that recognition is not given to partial implementation of best practices.

Table 2 indicates that none of the Australian states in the comparison have current legislation or policies that mirror those identified as world leading. Detailed analysis (Section 7) showed that New South Wales is the only state with a policy that partially complies with the landfill levy criteria through the implementation of a rebate scheme. The research did identify the future intentions of most states to improve their rates of CCDD waste dumping. In terms of overall strategy, South Australia's zero waste strategy most closely resembles best practice, although not to as high a level of inclusion.

The differences in recycling rates between the Netherlands and Denmark and Australia is a little surprising given that the overriding philosophies are all very similar. As previously noted, the Dutch approach is based on Lansink's ladder, and the other jurisdictions under consideration have adopted similar approaches. The waste hierarchy diagram (Fig. 4) from South Australia's zero waste strategy ${ }^{36}$ is a reasonable embodiment of the principles underpinning all of the states' waste policies.

One area not directly addressed in the identified best practice criteria is waste avoidance. While the policies encourage ex post waste avoidance through material bans and high levies, they do not directly engage with the avoidance issue and suggest solutions. This research found that the ex ante strategy of designing for disassembly was being used successfully in a range of industries and that it should have a place within construction by the avoidance of waste through careful preparation at the design phase of a product.

Guidelines have to be developed for application in the building industry to assist in designing for disassembly. Possible improvements to current practice in the construction industry include $^{4}$

(a) minimise different types of materials, leading to easier sorting for recycling, greater quantities of recycling and simplified transportation (b) avoid hazardous materials because of difficulties in their treatment and recycling

(c) understand standard recycling practice and recommend materials accordingly

(d) ensure materials are joined in easily separable ways

(e) avoid designing with secondary finishes or coatings

(f) identify materials using markings that indicate standards in order to increase confidence in reuse

(g) keep the number of components to a minimum; create greater numbers of fewer types of components to improve reuse or recycling

(h) design using mechanical connections such as bolts and screws rather than chemical connections that contaminate materials and make disassembly difficult.

As Fig. 5 illustrates, implementation of a design strategy with a view to disassembly would alter the existing 'once-only' materials lifecycle currently common in construction to a repetitive cycle where disassembly, reuse and recycling were the norm. ${ }^{4}$ Such a strategy and resultant reduction in CED waste would pose new challenges, creating a built environment where

(a) the majority of existing structures and their components would not have been designed for disassembly

(b) the necessary tools for disassembly would not yet exist

(c) current costs for landfilling of CED waste would be judged to be too low to act as a deterrent

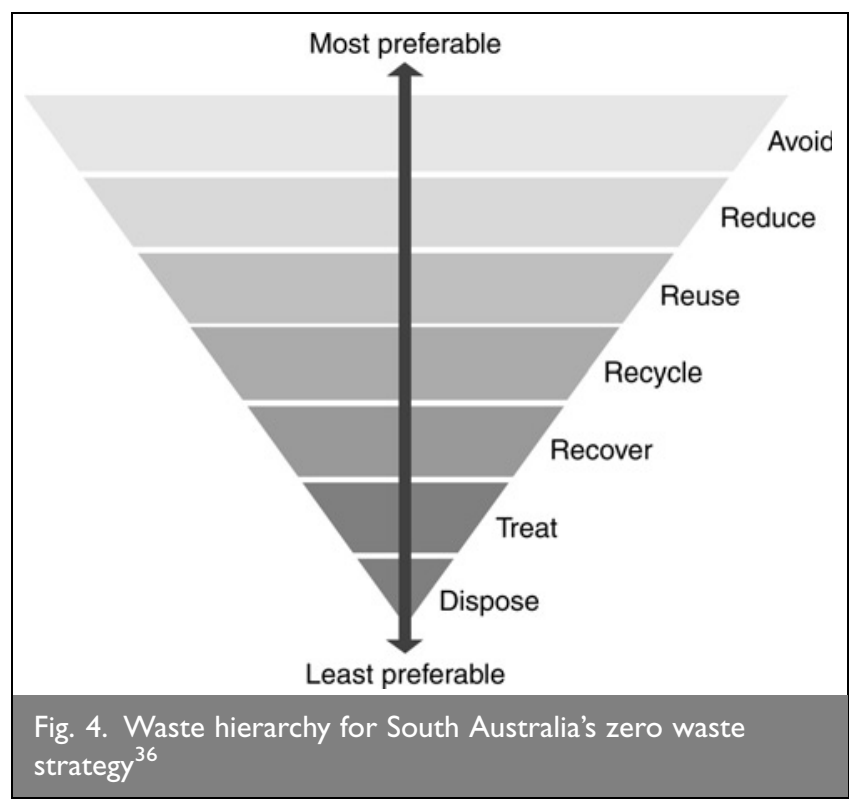




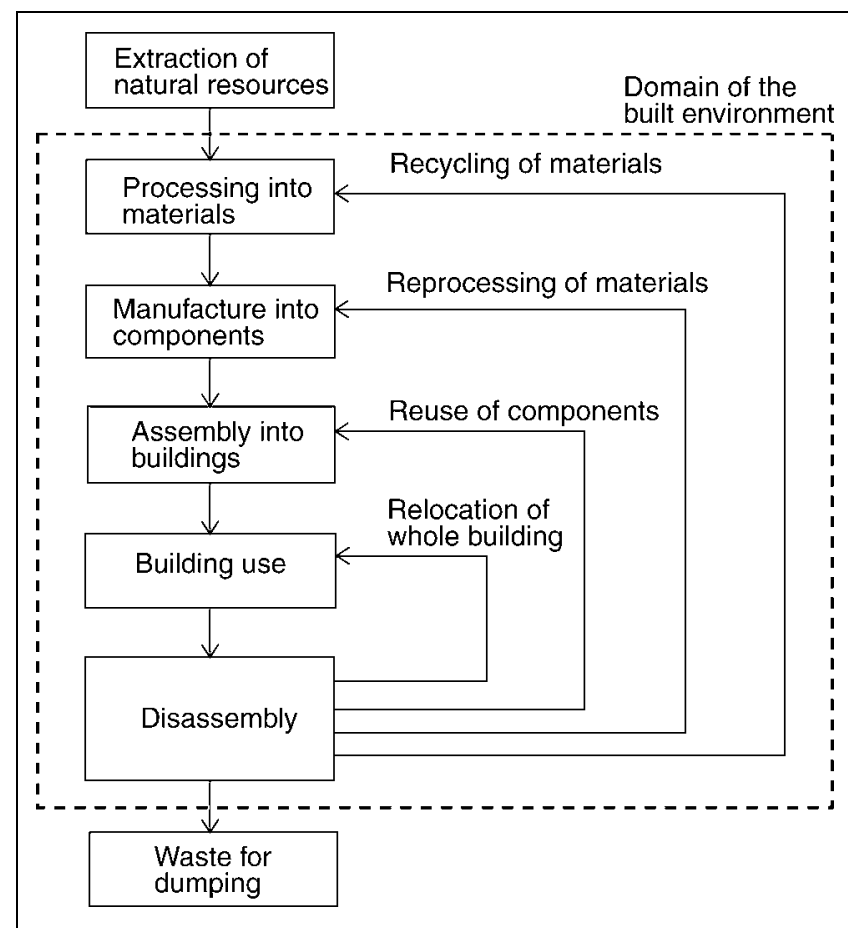

Fig. 5. Lifecycle of materials using design for disassembly

(d) additional time and consequent cost would be required for the disassembly of buildings and segregation of materials

(e) certification of building components would not always be possible

$(f)$ existing building codes would not easily accommodate the use of recycled materials or components into new works. ${ }^{4}$

The introduction of design for disassembly into the construction industry would alter the waste philosophies discussed earlier. Waste avoidance would replace waste reduction as the strategy of choice. The new design philosophy, based on design for disassembly, would resemble the proposed waste hierarchy of the government of South Australia (Fig. 4). ${ }^{36}$

Transplanting design for disassembly principles into a construction industry context presents serious challenges because of the differences between manufacturing and construction. Of particular note are

(a) the difficulty of labelling individual components and products with meaningful recycling data

(b) the high levels of use of generic and composite materials in certain forms of construction

(c) the disparity between as-designed/as-specified documentation and the as-built reality, where equal and approved and unauthorised material/product substitutions occur

(d) the lack of a single point of responsibility for coordinating the reuse/recycling process for a particular building

(e) the future-proofing of buildings in terms of toxicity, i.e. monitoring the use of materials and coatings that are currently considered safe and acceptable, but which may later come to be regarded as hazardous to health or the environment.

It is also interesting to note that the design for disassembly literature relating to manufacturing (e.g. Beitz ${ }^{37}$ ) makes considerable reference to the process of refurbishing items for re-introduction into service. It has long been recognised that the costs associated with the refurbishment of existing buildings tend to be disproportionately high, often rendering the process uneconomic and resulting in the demolition of an old building and construction of a new one in its place.

Certain new technologies have the potential to offer solutions to some of these challenges, in particular

(a) the use of building information models to document and record the as-built project, including all the necessary recycling/reuse information relating to materials and products

(b) the use of bar coding and embedded microchips to label materials and products in situ within a building. ${ }^{38}$

\section{CONCLUSION}

Previous research has identified the negative impact of CAD wastes on environmental and urban sustainability. This has inevitably meant that more emphasis is being placed on the recycling and reuse of waste. Australia's poor record in comparison to other countries can be attributed to the nature of the various governments' policies.

A policy analysis from around the world has identified the Netherlands and Denmark as demonstrating best practice, thus setting the benchmark for other countries. The analysis identified criteria that can be used to drive a successful waste management strategy for nations such as Australia. These criteria included levy systems to encourage recycling, bans on the disposal of recyclable wastes to landfill, the need for waste segregation or separation and a system of recycled materials certification to encourage the development of markets for their use. However, it was not possible to discern any overt attempt to encourage design for disassembly.

A policy comparison of Australian states found that none imposed legislation to match the benchmark practices. This result highlights the fact that federal, state and local government policies are ambiguous and ineffective with regard to C\&D waste management.

\section{REFERENCES}

1. Knecht B. Designing for disassembly and deconstruction. Architectural Record, 2004, 192, No. 10, 181-189.

2. Reddrop A., Ryan C. and Walker-Morison A. Housing Construction Waste: A Research Study by the National Key Centre for Design at RMIT. Australian Government Publications Service, Canberra, 1997.

3. Graham P., Prasad D. and Blair J. Sustainable Cities 2025. House of Representatives Standing Committee on Environment and Heritage, Canberra, 2003.

4. CROWTHER P. Building deconstruction in Australia. International Council for Research and Innovation in Building Construction (CIB) Task Group 39: Deconstruction (Kibert C. J. and Chini A. R. (eds)). CIB, Rotterdam, 2000, pp. 14-44.

5. RItchIE M. NSW Response to the Productivity Commissioner. Waste Management Association of Australia, Sydney, 2006.

6. Stern N. Stern Review: The Economics of Climate Change. Cambridge University Press, Cambridge, 2007. 
7. Teo M. and Loosemore M. A theory of waste behaviour in the construction industry. Construction Management and Economics, 2001, 19, No. 7, 741-751.

8. Kibert C. J. and Chini A. R. Introduction: deconstruction as an essential component of sustainable construction. International Council for Research and Innovation in Building Construction (CIB) Task Group 39: Deconstruction (Kibert C. J. and Chini A. R. (eds)). CIB, Rotterdam, 2000, pp. 6-13.

9. Vercruysse J.-P. A cleaner greener Europe. 2004, LIFE Focus, 1-28.

10. Ministry of Housing, Spatial Planning and the EnVIRONMEnt. VROM Construction and Demolition Waste. VROM, The Hague, 2001.

11. Te Dorsthorst B. J. H. and Kowalczyk T. Design for recycling. CIB Task Group 39-Deconstruction Fourth Annual Meeting (KiberT C. J. (ed.)). CIB, Rotterdam, 2003.

12. Crowther P. Building disassembly and the lessons of industrial ecology. International Council for Research and Innovation in Building Construction (CIB) Conference on Shaping the Sustainable Millennium: Collaborative Approaches. CIB, Rotterdam, 2000.

13. Peng C. L., Scorpio D. E. and Kibert C. J. Strategies for successful construction and demolition waste recycling operations. Construction Management and Economics, 1997, 15, No. 1, 49-58.

14. McDonough W. and Braungart M. Cradle to Cradle: Remaking the Way we Make Things. North Point Press, New York, 2002.

15. McDonald B. and Smithers M. Implementing a waste management plan during the construction phase of a project: a case study. Construction Management and Economics, 1998, 16, No. 1, 71-78.

16. Lingard H., Graham P. and Smithers G. Employee perceptions of the solid waste management system operating in a large Australian contracting organization: implications for company policy implementation. Construction Management and Economics, 2000, 18, No. 4, 383-393.

17. Saunders J. and Wynn P. Attitudes towards waste minimisation amongst labour only sub-contractors. Structural Survey, 2004, 22, No. 3, 148-155.

18. CROWTHER P. Design for buildability and the deconstruction consequences. Proceedings of CIB Task Group 39Deconstruction, Annual Meeting 2002. CIB, Karlsruhe, 2002, CIB report 272.

19. Newton P. W. Australia State of the Environment Report 2001. Commonwealth Science and Industry Research Organisation, 2001. See http://www.deh.gov.au/soe/2001/ settlements/settlements05-3b.html for further details. Accessed 01/03/2006.

20. Bell N. and mcWhinney S. Waste Reduction Guidelines. Natural Heritage Trust Waste Management Awareness Program, Commonwealth Department of the Environment and Heritage, 2001.
See http://www.environment.gov.au/epg/wastewise for further details. Accessed 01/03/2006.

21. Department of Environment and Conservation (NSW). NSW Government Policy, 2005. See http://www.wrapp.nsw. gov.au/whatis/aboutwrapp.shtml for further details. Accessed 01/03/2006.

22. BYLINSKY G. Manufacturing for reuse. Fortune, 1995, 131, No. 2, 102-112.

23. Eikelboom R. T., Ruwiel E. and Goumans J. The building materials decree: an example of a Dutch regulation based on the potential impact of materials on the environment. Waste Management, 2001, 21, No. 3, 295-302.

24. Environmental Protection Agency. Waste Hierarchy, 2006. See http://www.mst.dk/homepage/ for further details. Accessed 28/05/2006.

25. HJelmar 0. Waste management in Denmark. Waste Management, 1996, 16, No. 5, 389-394.

26. Ministry of Housing, Spatial Planning and the Environment. National Waste Management Plan: Part 1 Policy Framework. VROM, The Hague, 2001.

27. EcoRecycle Victoria. Towards Zero Waste Strategy. The State of Victoria, Melbourne, 2005.

28. Strauss A. and Corbin J. Basics of Qualitative Research: Grounded Theory Procedures and Techniques. Sage, Newbury Park, 1990.

29. Ezzy D. Qualitative Analysis: Practice and Innovation. Allen At Unwin, Sydney, 2002.

30. Kellehear A. The Unobtrusive Researcher: A Guide to Methods. Allen \& Unwin, Sydney, 1993.

31. Manuel J. S. Unbuilding for the environment. Environmental Health Perspectives, 2003, 111, No. 16, 880-887.

32. Ministry of Housing, Spatial Planning And the Environment. The Building Materials Decree. 2006. See http://international.vrom.nl/Docs/internationaal/ BMD_broch.pdf for further details. Accessed 30/05/2006.

33. Productivity Commission. Waste Management, Draft Report. Commonwealth of Australia, Canberra, 2006.

34. Resource NSW. NSW Waste Avoidance and Resource Recovery Strategy 2003: Summary. Department of Environment and Conservation (NSW). See http://www. resourcensw.gov.au/data/strategy/Summary\%202003\%20 web.pdf for further details. Accessed 06/06/2006.

35. Department of Environment and Conservation (NSW). Waste Reduction and Purchasing Policy, 2006. See http:// www.wrapp.nsw.gov.au/ for further details. Accessed 06/ 06/2006.

36. Zero WASte SA. South Australia's Waste Strategy 2005-2010. Government of South Australia, Adelaide, 2005.

37. BeItz W. Designing for ease of recycling. Journal of Engineering Design, 1993, 4, No. 1, 11-23.

38. Bulmer T. and Brewer G. Improving the uptake of IT in industry. Proceedings of the 5th Annual CIIA Conference, Brisbane, 2000, www.ciia.qut.com/conference/BULMER, TERRY.doc (accessed 05/11/2000).

\section{What do you think?}

To comment on this paper, please email up to 500 words to the editor at journals@ice.org.uk

Proceedings journals rely entirely on contributions sent in by civil engineers and related professionals, academics and students. Papers should be 2000-5000 words long, with adequate illustrations and references. Please visit www.thomastelford.com/journals for author guidelines and further details. 